\title{
Age differences in suicide methods
}

\begin{abstract}
Objective: There is not adequate research on suicide methods by age in Turkey. The purpose of the present study is to investigate whether there is any change in suicide methods by age over time and whether suicide methods significantly differ by age.

Method: Secondary data about suicide from 2007 to 2015 were obtained from the Turkish Statistical Institute. The number of suicide cases was 25,696. Direct standardization method was used to calculate suicide rates. Line charts were plotted to reveal the trends in suicide methods by age. Then, one-way anova (ANOVA) test was conducted to test whether suicide methods significantly differed by age.
\end{abstract}

Results: Among all ages, hanging was the most common suicide method, followed by firearm, jumping, intoxication, and cutting/burning among all age groups. Moreover, all of the other suicide methods increased except for cutting/burning among those aged 1524 years, except for firearm among those aged 25-44 years, except for hanging among those aged 45-64 years. Among those aged 65 and older, suicide by hanging decreased, however, suicide by other methods overall remained stable. The results also showed that with increasing age, suicide by hanging, jumping, and cutting increased, while suicide by firearm and intoxication decreased. In addition, the results of ANOVA test indicated that except for intoxication, all other suicide methods differed significantly by age groups.

Conclusions: Hanging, jumping, and cutting/burning were the most popular methods among older people, while firearm and intoxication were more popular among younger people.

Keywords: suicide, suicide method, age, firearm, hanging, cutting/burning, intoxication, jumping

\section{Introduction}

Suicide, defined as killing oneself knowingly and consciously ${ }^{1,2}$ is one of the leading causes of death across the world. ${ }^{3}$ In 2015, about 800,000 people committed suicide. ${ }^{4}$ It is important to note that the global suicide rate per 100,000 people is $16 .{ }^{5}$ Although suicide rate (around 4 per 100,000 people) is lower in Turkey ${ }^{6}$ such as in other countries, suicide is considered a serious public health issue that needs to addressed. Previous studies have shown that suicide rates are associated with age. ${ }^{7}$ More specifically, studies have suggested that suicide rates are higher for older people. ${ }^{8-16}$ Beyond the causes of suicide, the reasons for higher suicide rates for older people may be attributable to the lethality of chosen suicide methods such as firearm, hanging, jumping etc. ${ }^{17-22}$ The most common suicide methods across the world include poisoning, hanging, drowning, firearm, burning, cutting/piercing, jumping, and vehicular impact. ${ }^{5}$ In Turkey, of suicide methods, hanging was the most common suicide method, followed by firearms, jumping from high places, intoxication, drowning, cutting, and vehicular impact. ${ }^{23,24}$ Suicide method is primarily driven by its availability and accessibility to people with certain ages. Studies have shown that suicide methods vary by age groups. For instance, Baker et al. ${ }^{8}$ conducted a study in America, and found that between 2000 and 2010 , the most common suicide methods were firearms and hanging respectively for those including aged 15-24 and 25-44 years, and was firearm, followed by poisoning for those including aged 45-59 and 60-69, and was firearm for those aged 70 and above. Another study conducted in Iran using the suicide data between 2006 and 2010 found that younger individuals with mean age of 27.1 committed suicide by firearms whilst people with mean age around 32 used hanging and poisoning to commit suicide. ${ }^{25}$ Furthermore, the suicide data between 2000 and 2009 in Canada indicated that the most common
Volume 6 Issue 6 - 2018

\section{Mustafa Demir \\ State University of New York at Plattsburgh, USA}

Correspondence: Mustafa Demir, State University of New York at Plattsburgh, USA, Tel + 15185643305 Emailmdami002@plattsburgh.edu

Received: June 05, 2017 | Published: December II, 2018 suicide method was hanging for those aged 15-39 years, hanging and poisoning for those aged 40-59 years, and hanging, firearm, and poisoning respectively for those aged 60 and older. ${ }^{26}$ In other words, in Canada, with increase in age, the use of hanging declined, however, the use of firearm rose. In addition, the study conducted in Israel using the suicide data from 1981 to 2008 showed that except for firearm, all other suicide methods including hanging, jumping, poisoning were used by those aged 65 and older more than those including aged 15-24, 25-44, and 45-64 years. ${ }^{27}$ Finally, the study on the trends in suicide methods in South Korea and Japan showed that hanging was the most common method among those aged 65 and older. ${ }^{28}$ Like in other countries, suicide methods may also vary by age in Turkey. However, there is scant research that has investigated suicide methods by age in depth by using statistical analyses in Turkey. In addition, there might be changes in the trends in suicide methods by age over time, which should be investigated empirically. Analysis of such trends may shed light on identifying popularity of certain suicide methods, and developing new interventions to prevent further suicides accordingly. ${ }^{29}$ To fill the gap in the literature in the context of Turkey, the present study examined suicide methods by age and the trends in suicide methods by age over time. More specifically, the study was designed to seek to address the following research questions:

I. Is there any change in the trends in suicide methods by age over time?

II. Is there a significant difference in suicide methods among age groups?

The findings of the study may have significant impact on new suicide preventive policies. 


\section{Methods}

\section{Data}

The data were extracted from the Turkish Statistical Institute (TUIK) website, which collects official statistics from the other governmental agencies. ${ }^{30}$ Specifically, for each year from 2007 to 2015 , the number of suicide cases, the number of suicide cases by age and method, ${ }^{6}$ and population data ${ }^{31}$ were obtained from the TUIK. Afterwards, the data were merged. The number of suicide cases between 2007 and 2015 was 25,696.

\section{Measures}

In this study, two variables were used: suicide method and age. A five category of suicide method was created from the original suicide method with ten categories. More specifically, suicide method had originally ten categories $(1=$ hanging $2=$ taking chemicals $3=$ throwing from a high place $4=$ drowning $5=$ =firearm $6=$ burning $7=$ sharp instrument $8=$ natural gas, jpg etc. $9=$ throwing off a train or another motorized vehicle $10=$ other). The categories including "taking chemicals" and "natural gas, jpg etc." were combined to a new category called "intoxication". The categories including "sharp instrument" and "burning" were combined into a new category called "cutting/burning". The categories include "throwing from a high place", drowning and "throwing off a train or another motorized vehicle" were collapsed into one category called"jumping". The new categories of suicide method had five categories (1=hanging $2=$ intoxication $3=$ =firearm $4=$ jumping $5=$ cutting/burning). The category of "other" was excluded due to small number of suicide cases. A four group of age was created from the original age group with fourteen categories. Specifically, age had originally fourteen categories $(1=<15 \quad 2=15-19 \quad 3=20-24 \quad 4=25-29 \quad 5=30-34 \quad 6=35-39$ $7=40-44 \quad 8=45-49 \quad 9=50-54 \quad 10=55-59 \quad 11=60-64 \quad 12=65-69 \quad 13=70-74$ $14=75+)$. Age was collapsed into seven categories $(1=<20 \quad 2=20-29$ $3=30-394=40-495=50-596=60-697=70+)$. Age was collapsed into four categories $(1=15-242=25-443=45-644=65+)$. Age group $<15$ was excluded from the new age groups for two reasons: First, the number of suicide cases committed by those aged $<15$ was low. Second and most importantly, age group $<15$ covers the age ranging from 1 to 15. Suicide cannot be committed by those who are at certain age (i.e., a three years child). Including the age group $<15$ would also affect the measurement validity. Suicide rate was standardized to control for the effects of population differences for specific groups by using the direct standardization method. Specifically, the direct standardization method was used to calculate age-adjusted suicide rate and age-specific suicide rate for each year instead of crude suicide rate. ${ }^{32}$ According to Anderson and Rosenberg ${ }^{32}$ crude or unadjusted suicide rate is obtained by dividing the number of suicides by the population at risk, and multiplied by generally 100,000, and an age-specific suicide rate is simply a crude suicide rate for a specific age group. In other words, age-specific suicide rate was calculated by dividing the number of suicides for each age group by the corresponding population in that age group, and multiplying by 100,000. Age-adjusted suicide rate was calculated by simply multiplying the age specific suicide rates by the corresponding proportion of the standard population in that age group, and sum these products across four age groups. ${ }^{32}$

\section{Analytical strategy}

The analyses consisted of several stages: First, a descriptive statistics about suicide by age and suicide methods were provided. Furthermore, line charts were plotted to reveal the trends between
2007 and 2015 about suicide method by all ages, average suicide method by age, and suicide method for each age group. Finally, oneway anova (ANOVA) test was conducted to test whether suicide methods differed by age groups significantly by using Stata 14.2 version.

\section{Results}

Descriptive statistics was provided in table 1 . The results indicated that 25,696 people above 15 years old committed suicide between 2007 and 2015. Almost $40 \%$ of them were between 25 and 44 years old. About one fourth of them were between 15 and 24 years old and about one fourth of them were between 45 and 64 years old. Almost $12 \%$ of them were $65+$ years old. Hanging was the most common suicide method $(49.6 \%)$, followed by firearm $(25.8 \%)$, jumping (12.4\%), intoxication (7.5\%), and cutting/burning (1.7\%) Table 1. Figure1 shows the trends in suicide methods by all ages between 2007 and 2015. During the nine year period, among all ages, hanging was the most common suicide method, followed by firearm, jumping, intoxication, and cutting/burning. Over decade, although there were fluctuations in the use of hanging and firearm, there was a little bit increase in suicide by hanging and firearm. Suicide by jumping steadily increased. Intoxication decreased by 2009 , and then remained stable over time. Suicide by cutting/burning slightly increased. Figure 2 presents the trends in suicide methods by age groups from 2007 to 2015. Among those aged 15-24 years, hanging and firearm were the most common suicide methods over time. Although there were fluctuations in suicide by hanging and firearm, the use of both methods increased. Hanging and firearm peaked up in 2012 and 2013 respectively, and afterwards declined. Intoxication decreased until 2008, and then roughly, remained stable over time. Over time, jumping steadily increased, while cutting/burning decreased. Among those aged 25-44 years, hanging and firearm were also the most common suicide methods over time. Although there was up and down in suicide by hanging, an increase was observed. Suicide by jumping and cutting/burning steadily increased, while suicide by firearm remained stable. Suicide by intoxication decreased by 2012, and then increased. Among those aged 45-64 years, hanging was the most common suicide method over time although it peaked up in 2009, and then declined by 2011, again increased in 2012, and then declined. In recent years, suicide by firearm and jumping steadily and slightly increased. Overall, intoxication and cutting/burning remained stable. Among those aged 65 and older, similar to the other age groups, hanging was used most frequently to commit suicide over decade. Suicide by hanging declined by 2011, and afterwards increased in 2012, and then decreased. Other suicide methods including firearm, jumping, cutting/burning, and intoxication were overall stable although there were some fluctuations (Figure 2).

Figure 3 shows the averaged suicide method by age group between 2007 and 2015. According to Figure 3, suicide by hanging, jumping, and cutting/burning increased with increasing age. Specifically, hanging was the most popular method among those 65 and older, followed by 45-64, 15-24, and 25-44. In other words, hanging was the most common method used by those aged 45 years and older. Suicide by jumping was low by the age of 64 , then increased. Jumping was the most common method particularly among those aged 65 and older, followed by those aged 15-24 years. Suicide by cutting/burning increased slightly with the rise in age. Unlike suicide by hanging, jumping, cutting/burning, suicide by firearm and intoxication decreased with increasing age. In other words, firearm was the most common suicide method among those aged 15-24 years, while it was 
used less frequently by those aged 65 and older. Suicide by intoxication was more popular among those aged 15-24 years, followed by those aged 25-44, 45-64, and 65 and older. Table 2 presents the results of one-way anova (ANOVA) test. The results indicated that of suicide methods, except for suicide by intoxication $(\mathrm{F}(32,3)=2.9, \mathrm{p}=.051)$, hanging $(\mathrm{F}(32,3)=43.0, \mathrm{p}<.001)$, jumping $(\mathrm{F}(32,3)=15.7, \mathrm{p}<.001)$, firearm $(\mathrm{F}(32,3)=28.3, \mathrm{p}<.001)$, and cutting/burning $(\mathrm{F}(32,3)=11.1$, $\mathrm{p}<.001$ ) differed significantly by age groups (Table 2 ). Specifically, suicide by hanging differed significantly between age groups including $65+$ and all other age groups, and between 25-44 and 45-64. However, suicide by hanging did not differ significantly between those aged $15-$ 24 and the age groups including 25-44, and 45-64. Moreover, suicide by hanging was the highest among those aged 65 and older $(\mathrm{M}=3.50$, $\mathrm{SD}=0.30)$, followed by 45-64 $(\mathrm{M}=2.73, \mathrm{SD}=0.32), 25-44(\mathrm{M}=2.26$, $\mathrm{SD}=0.15)$, and $15-24(\mathrm{M}=2.41, \mathrm{SD}=0.19)$. In other words, suicide by hanging increased with the increase in age. Suicide by jumping differed significantly between those aged $65+$ and all other age groups. However, there was no significant difference between those aged 1524 and the age groups including 25-44 and 45-64, and between 25-44 and 45-64. In addition, suicide by jumping was the highest among those aged $65+(\mathrm{M}=0.90, \mathrm{SD}=0.11)$, followed by $15-24(\mathrm{M}=0.68$, $\mathrm{SD}=0.15), 25-44(\mathrm{M}=0.59, \mathrm{SD}=0.10)$, and 45-64 $(\mathrm{M}=0.55, \mathrm{SD}=0.11)$. In other words, suicide by jumping was prevalent among older and younger people. Suicide by firearm differed significantly between those aged 15-24 years and all other age groups. However, there was no statistically significant difference between those aged 25-44 and the age groups including 45-64 and 65+, and between 45-64 and 65+. Additionally, suicide by firearm was the most common among those aged $15-24$ years $(\mathrm{M}=1.77, \mathrm{SD}=0.28)$, followed by $25-44(\mathrm{M}=1.27$, $\mathrm{SD}=0.04), 45-64(\mathrm{M}=1.12, \mathrm{SD}=0.15)$, and $65+(\mathrm{M}=1.03, \mathrm{SD}=0.19)$. That is, suicide by firearm decreased with the increase in age. Suicide by cutting/burning differed significantly between those aged $65+$ and all other age groups, and between 15-24 and 45-64. However, the difference between 15-24 and 25-44, and between 25-44 and 45-64 was not statistically significant. Moreover, suicide by cutting/burning was the highest among those aged $65+(\mathrm{M}=0.13, \mathrm{SD}=0.04)$, while it was the lowest among those aged $15-24$ years $(\mathrm{M}=0.03, \mathrm{SD}=0.05)$. It was almost same for those aged 45-64 $(\mathrm{M}=0.08, \mathrm{SD}=0.03)$, and 25$44(\mathrm{M}=0.08, \mathrm{SD}=0,02)$. Stated differently, suicide by cutting/burning increased with the increase in age. Although there was no statistically significant difference in suicide by intoxication among age groups, those aged 15-24 years had the highest rate $(\mathrm{M}=0.54, \mathrm{SD}=0.31)$, while those aged $45-64(\mathrm{M}=0.31, \mathrm{SD}=0.07)$ had the lowest rate. Those aged 25-44 $(\mathrm{M}=0.36, \mathrm{SD}=0.16)$ and $65+(\mathrm{M}=0.36, \mathrm{SD}=0.09)$ had similar rates. In other words, suicide by intoxication was popular among younger people.

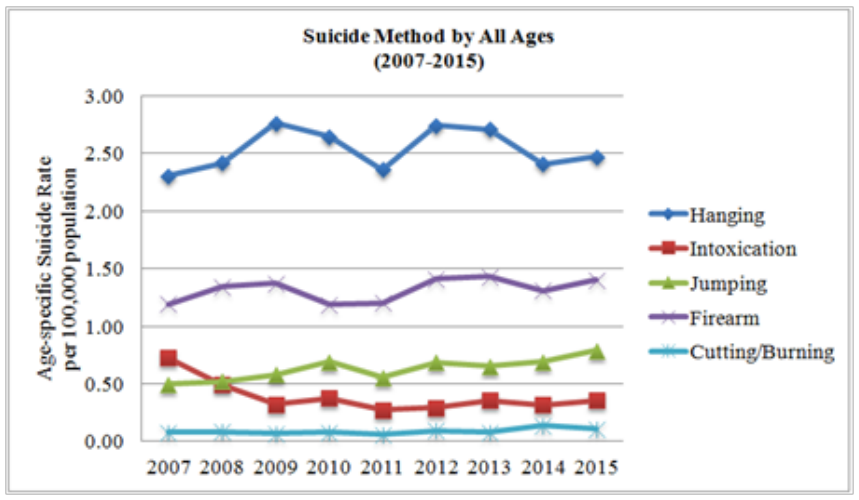

Figure I Trends in suicide methods by all ages between 2007 and 2015.
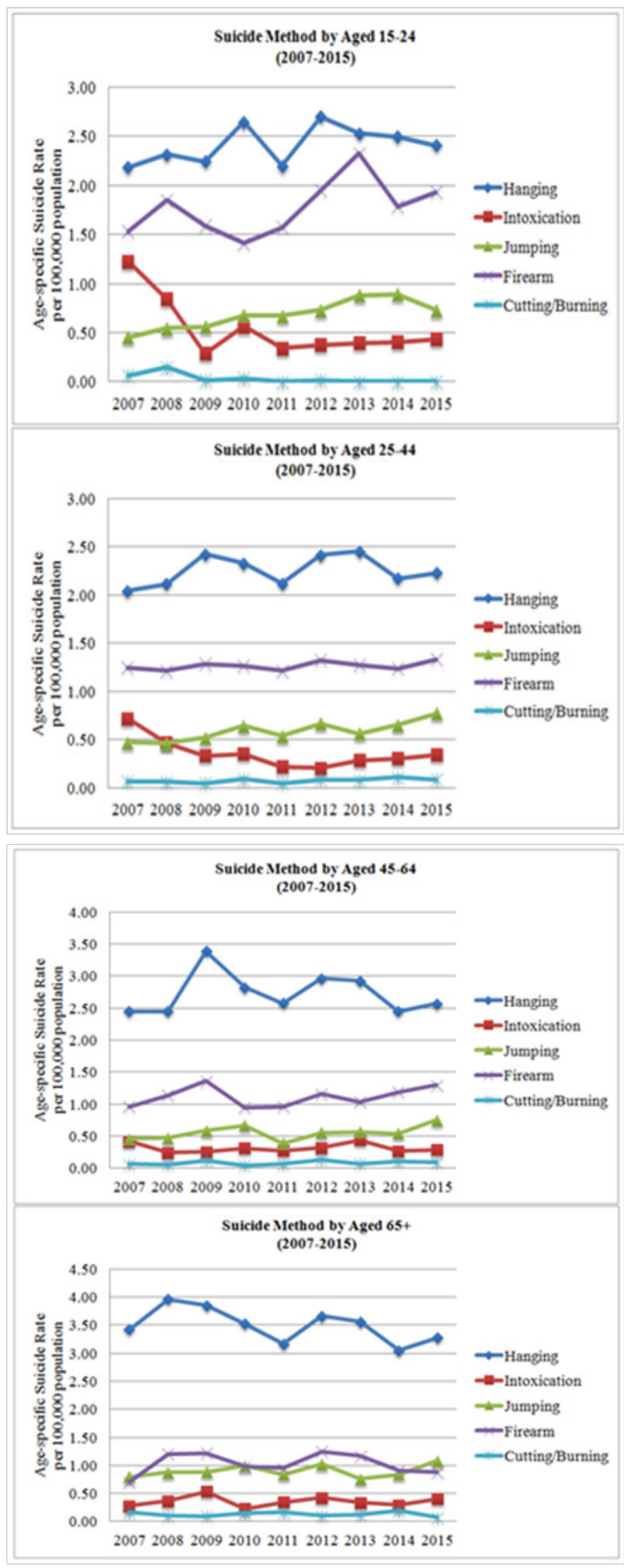

Figure 2 Trends in suicide methods by age groups between 2007 and 2015. 


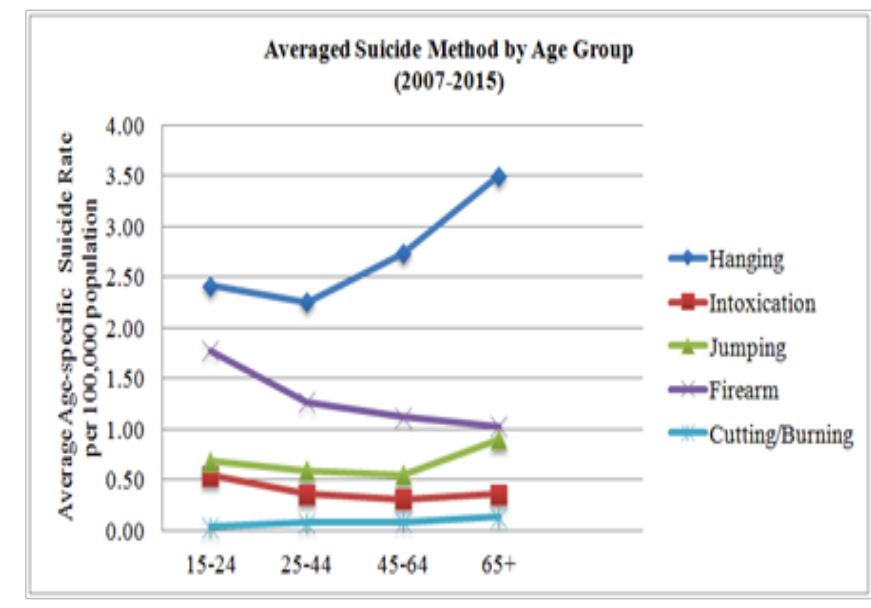

Figure 3 Averaged suicide methods by age group between 2007 and 2015 .
Table I Descriptive statistics

\begin{tabular}{lll}
\hline Variables & Attributes & $\%$ \\
\hline \multirow{2}{*}{ Age Group } & & \\
& $15-24$ & 25.2 \\
& $25-44$ & 38.2 \\
& $45-64$ & 24.8 \\
& $65+$ & 11.8 \\
Suicide Method & \\
& Hanging & 49.6 \\
& Intoxication & 7.5 \\
& Jumping & 12.4 \\
& Firearm & 25.8 \\
& Cutting/Burning & 1.7 \\
\hline
\end{tabular}

Note. $\mathrm{N}=25,696$

Table 2 Results of one-way Anova: suicide methods by age groups

\begin{tabular}{|c|c|c|c|c|c|c|c|c|c|c|}
\hline \multirow[b]{2}{*}{$\begin{array}{l}\text { Suicide } \\
\text { Methods }\end{array}$} & \multirow[b]{2}{*}{ Age } & \multirow[b]{2}{*}{$\mathbf{M}$} & \multirow[b]{2}{*}{ SD } & \multirow[b]{2}{*}{$F(32,3)$} & \multirow[b]{2}{*}{$\begin{array}{l}(15-24)- \\
(25-44)\end{array}$} & \multirow[b]{2}{*}{$(15-24)-(45-64)$} & \multicolumn{3}{|c|}{ Mean Difference } & \multirow[b]{2}{*}{$\begin{array}{l}(45-64)- \\
(65+)\end{array}$} \\
\hline & & & & & & & $(15-24)-(65+)$ & $\begin{array}{l}(25-44)- \\
(45-64)\end{array}$ & $\begin{array}{l}(25-44)- \\
(65+)\end{array}$ & \\
\hline \multirow[t]{5}{*}{ Hanging } & & & & $43.0 * * *$ & 0.16 & -0.32 & $-1.08 * * *$ & $-0.48^{* *}$ & $-1.24 * * *$ & $-0.77 * * *$ \\
\hline & $15-24$ & 2.41 & 0.19 & & & & & & & \\
\hline & $25-44$ & 2.26 & 0.15 & & & & & & & \\
\hline & $45-64$ & 2.73 & 0.32 & & & & & & & \\
\hline & $65+$ & 3.5 & 0.3 & & & & & & & \\
\hline \multirow[t]{5}{*}{ Intoxication } & & & & 2.9 & 0.18 & 0.23 & 0.19 & 0.05 & 0 & -0.04 \\
\hline & $15-24$ & 0.54 & 0.31 & & & & & & & \\
\hline & $25-44$ & 0.36 & 0.16 & & & & & & & \\
\hline & $45-64$ & 0.31 & 0.07 & & & & & & & \\
\hline & $65+$ & 0.36 & 0.09 & & & & & & & \\
\hline \multirow[t]{5}{*}{ Jumping } & & & & $15.7 * * *$ & 0.09 & 0.13 & $-0.22 * *$ & 0.04 & $-0.3 \mid * * *$ & $-0.35 * * *$ \\
\hline & $15-24$ & 0.68 & 0.15 & & & & & & & \\
\hline & $25-44$ & 0.59 & 0.1 & & & & & & & \\
\hline & $45-64$ & 0.55 & 0.11 & & & & & & & \\
\hline & $65+$ & 0.9 & 0.11 & & & & & & & \\
\hline \multirow[t]{5}{*}{ Firearm } & & & & $28.3^{* * *}$ & $0.50 * * *$ & $0.66 * * *$ & $0.74 * * *$ & 0.15 & 0.24 & 0.09 \\
\hline & $15-24$ & $\mathrm{I} .77$ & 0.28 & & & & & & & \\
\hline & $25-44$ & 1.27 & 0.04 & & & & & & & \\
\hline & $45-64$ & 1.12 & 0.15 & & & & & & & \\
\hline & $65+$ & 1.03 & 0.19 & & & & & & & \\
\hline \multicolumn{2}{|c|}{ Cutting/Burning } & & & $\mid \mathrm{I} . \mathrm{I}^{* * *}$ & -0.04 & $-0.05^{*}$ & $-0.10 * * *$ & -0.01 & $-0.05^{*}$ & $-0.05^{*}$ \\
\hline
\end{tabular}


Table Continued

$\begin{array}{ccc}15-24 & 0.03 & 0.05 \\ 25-44 & 0.08 & 0.02 \\ 45-64 & 0.08 & 0.03 \\ 65+ & 0.13 & 0.04\end{array}$

Note. $\mathrm{N}=25,696 . *_{\mathrm{p}}<.05 . * * \mathrm{p}<.01 . * * * \mathrm{p}<.001$. Bold indicates significance.

\section{Discussion}

The present study examined the trends in suicide methods by age groups and whether suicide methods differed significantly among age groups. The trends in suicide methods suggested that hanging was the most common suicide method, followed by firearm, jumping, intoxication, and cutting/burning among all age groups between 2007 and 2015. Among those aged 15-24 years, except for cutting/ burning, suicide by hanging, firearm, jumping, and intoxication (particularly in recent years) increased. Among those aged 25-44 years, suicide by hanging, jumping, cutting/burning, and in recent years, suicide by intoxication increased. Among those aged 45-64 years, suicide by hanging decreased, while suicide by other methods increased. Finally, among those aged 65 and older, suicide by hanging decreased, however, suicide by other methods overall remained stable. The results also showed that with increasing age, suicide by hanging, jumping, and cutting increased, while suicide by firearm and intoxication decreased. Hanging, jumping, and cutting/burning were the most popular methods among older people, while firearm and intoxication were more popular among younger people. In addition, the results of ANOVA test indicated that except for intoxication, all other suicide methods differed significantly by age groups. The results of ANOVA test also suggested that among age groups, the most common suicide methods were hanging, jumping, and cutting/ burning for older people, firearm and intoxication for younger people. The findings are somewhat consistent with the existing literature. One finding is that hanging and firearm are used mostly by those aged 1524 years. This is consistent with some of the results of the previous research. $^{8-27}$ Another finding is that older people use hanging most frequently to commit suicide. Although this finding is consistent with some of the previous studies ${ }^{25-27}$ it contradicts with some of the findings of the previous research. ${ }^{8}$ The findings have some important policy implications. Suicide method is the most important factor that leads suicidal thoughts to suicidal acts since the outcomes of suicidal acts depend on the lethality of chosen suicide method. ${ }^{19-21}$ Therefore, suicide rates may be reduced by removing the opportunities to commit suicide. ${ }^{33-36}$ Specifically, stricter gun control policies for particularly young people may lower suicide rates by firearm. ${ }^{37-39}$ Suicide by hanging may be prevented by removing the opportunities such as hooks from homes. ${ }^{40}$ Suicide by jumping may be prevented by installing fences in the high buildings and bridges, ${ }^{41-44}$ along railroad tracks and roads in which suicides mostly occur. ${ }^{45}$ The study has some limitations. The data were agency data, whose accuracy is questionable. In addition, suicide may be underreported so that the data may not reflect the actual number of suicides. Future studies should examine suicide methods by gender and age, and causes of suicide among gender and age groups to understand the other aspects of suicide. In addition, an international comparative study on suicide methods by gender and age groups should be conducted.

\section{Acknowledgments}

None

\section{Conflicts of interest}

The author declares that there is no conflicts of interest.

\section{References}

1. Crosby AE, Ortega L, Melanson C. Self-directed Violence Surveillance: Uniform Definitions and Recommended Data Elements, Version 1.0. Centers for Disease Control and Prevention, National Center for Injury Prevention and Control. 2011.

2. Shneidman E. Definition of suicide. Sucidology. 1977;1-272.

3. WHO. Suicide. 2016a.

4. WHO. Global Health Observatory (GHO) Data. 2016b.

5. WHO. Data and statistics. 2014.

6. TUIK. Duties and Authorities. 2016a.

7. Shah A. The relationship between suicide rates and age: an analysis of multinational data from the World Health Organization. International Psychogeriatrics. 2007;19(06):1141-1152.

8. Baker SP, Hu G, Wilcox HC, et al. Increase in suicide by hanging/ suffocation in the US, 2000-2010. American journal of preventive medicine. 2013;44(2):146-149.

9. Bertolote JM, Fleischmann A. A global perspective in the epidemiology of suicide. Suicidology. 2002;7(2):6-8.

10. Curtin SC, Warner M, Hedegaard H. Suicide rates for females and males by race and ethnicity: United States, 1999 and 2014. Atlanta, GA: Centers for Disease Control and Prevention. 2016.

11. Durkheim E. Suicide. In: Spaulding JA, Simpson G. (Editors). Routledge. London. 1897.

12. Hyman J, Ireland R, Frost L, et al. Suicide Incidence and Risk Factors in an Active Duty US Military Population. American Journal Of Public Health. 2012;102(S1):S138-S146.

13. Krug EG, Dahlberg LL, Mercy JA, et al. World report on violence and health. World Health Organization, Geneva. 2002.

14. Segal DL, Needham TN. An Exploration of Gender Differences on the Reasons for Living Inventory among Older Adults. Death Studies. 2007;31(6):573-581.

15. Suicide Prevention Resource Center (SPRC). Suicide by Age. 2017b.

16. Suicide. Suicide Statistics. 2014.

17. Beautrais AL. Suicide and serious suicide attempts in youth: a multiple-group comparison study. American Journal of Psychiatry. 2003;160(6):1093-1099. 
18. Card JJ. Lethality of suicidal methods and suicide risk: two distinct concepts. OMEGA — Journal of Death and Dying, 1974;5(1):37-45.

19. Hawton K. Restricting access to methods of suicide. Rationale and evaluation of this approach to suicide prevention. Crisis. 2007;28(1):4-9.

20. Spicer RS, Miller TR. Suicide acts in 8 states: incidence and case fatality rates by demographics and method. American Journal of Public Health. 2000;90(12):1885-1891.

21. Uribe IP, Blasco-Fontecilla H, Garcia-Pares G, et al. Attempted and completed suicide: Not what we expected? Journal of Affective Disorders. 2013;150(3):840-846.

22. Vyrostek SB, Annest JL, Ryan GW. Surveillance for fatal and nonfatal injuries, United States, 2001. MMWR Surveillance Summary. 2004;53(7):1-57.

23. TUIK. Suicide statistics 2011. Turkish Statistical Institute Printing Division. Ankara. 2011.

24. TUIK. Suicide statistics 2012. Turkish Statistical Institute News Release. No: 15853.2013.

25. Shojaei A, Moradi S, Alaeddini F, et al. Association between suicide method, and gender, age, and education level in Iran over 20062010. Asia $\square$ Pacific Psychiatry. 2014;6(1):18-22.

26. Statistics Canada. Suicide Rates: An Overview. 2015.

27. Katz B. Methods of suicide in old age in Israel: Age and gender differences. European Psychiatry. 2016;33:S752-S753.

28. Park S, Lee HB, Lee SY, et al. Trends in suicide methods and rates among older adults in South Korea: a comparison with Japan. Psychiatry investigation. 2016;13(2):184-189.

29. Kreitman N. The coal gas story. United Kingdom suicide rates, 1960-71. British journal of preventive \& social medicine. 1976;30(2):86-93.

30. TUIK. Vital Statistics. 2016 b.

31. TUIK. Address Based Population Registration System. 2016c.
32. Anderson RN, Rosenberg HM. Age standardization of death rates: implementation of the year 2000 standard. National vital statistics reports. 1998;47(3):1-17.

33. Clarke RV, Lester D. Suicide: closing the exits. Transaction Publishers. 2013.

34. Marzuk PM, Leon AC, Tardiff K, et al. The effect of access to lethal methods of injury on suicide rates. Archives of general Psychiatry. 1992;49(6):451-458.

35. Sarchiapone M, Mandelli L, Iosue M, et al. Controlling access to suicide means. International Journal of Environmental Research and Public Health. 2011;8(12):4550-4562.

36. Winokur G, Black DW. Suicide-what can be done? The New England Journal of Medicine. 1992;327(7):490-491.

37. Lester D. Gun Control. IN: Charles C Thomas. 1984.

38. Lester D. Controlling crime facilitators: Evidence from research on homicide and suicide. Crime Prevention Studies. 1993;1(1):35-54.

39. Lester D, Murrell ME. The Preventive Effect of Strict Gun Control Laws on Suicide and Homicide. Suicide \&Life-Threatening Behavior. 1982;12(3):131-140.

40. Lester D. Can we prevent suicide? AMS Press: New York, USA. 1989.

41. Bennewith O, Nowers M, Gunnell D. Effect of barriers on the Clifton suspension bridge, England, on local patterns of suicide. British Journal of Psychiatry. 2007;190:266-267.

42. Berman AL, O'Carroll PW, Silverman MM. Community suicide prevention. Suicide \& Life-Threatening Behavior. 1994;24:89-99.

43. Pelletier AR. Preventing suicide by jumping. Injury Prevention. 2007;13(1):57-59.

44. Reisch T, Michel K. Securing a suicide hot spot: Effects of a safety Net at the Bern Muenster Terrace. Suicide \& Life-Threatening Behavior. 2005;35(4):460-467.

45. Kerkhof A. Railway suicide. Crisis. 2003;24:47-48. 